EURNAI RIS'II
(Rekayasa Sistem dan Teknologi Informasi)
Vol.1 No.1 (2017) 58-63 | ISSN Media Elektronik : 2580-0760

\title{
Pengembangan SMS Gateway Layanan Informasi Akademik di STMIK GI MDP
}

\author{
Fransiska Prihatini Sihotang ${ }^{\mathrm{a}}$, Fithri Selva Jumeilah ${ }^{\mathrm{b}}$ \\ aProgram Studi Sistem Informasi, STMIK GI MDP, fransiskaps@mdp.ac.id \\ bProgram Studi Sistem Informasi, STMIK GI MDP, fithri.selva@mdp.ac.id
}

\begin{abstract}
Information technology can be utilized in education such as e-Learning and Academic Information System. STMIK GI MDP has applied information technology that provides ease for the dissemination of academic information to students. However, the parents of the students have not obtained the academic information of their children due to the lack of internet-related knowledge. Therefore, this study aims to create a service that is able to convey information to parents directly with SMS Gateway service. This research begins with the collection of user needs through observation techniques and interviews to academic staff and parents. Then performed the required feature analysis. Then the design of SMS Gateway application that will be embedded in existing academic applications and coding system. Gammu is used as a link between applications with mobile phones. The result of this research is the application of SMS Gateway service that can give the student academic information to the parents.
\end{abstract}

Keywords: SMS gateway, STMIK, MDP, Education, Gammu

\begin{abstract}
Abstrak
Teknologi informasi dapat dimanfaatkan dalam dunia pendidikan seperti e-Learning maupun Sistem Informasi Akademik. STMIK GI MDP sudah menerapkan teknologi informasi yang memberikan kemudahan untuk penyebaran informasi akademik kepada mahasiswa. Namun, orang tua mahasiswa belum mendapatkan informasi akademik anaknya karena minimnya pengetahuan terkait internet. Oleh karena itu, penelitian ini bertujuan untuk membuat sebuah layanan yang mampu menyampaikan informasi kepada orang tua secara langsung dengan layanan SMS Gateway. Penelitian ini diawali dengan pengumpulan kebutuhan pengguna melalui teknik observasi dan wawancara kepada staf akademik dan orang tua. Lalu dilakukan analisis fitur yang dibutuhkan. Kemudian dilakukan desain aplikasi SMS Gateway yang akan ditanamkan pada aplikasi akademik yang sudah ada dan dilakukan pengkodean sistem. Gammu digunakan sebagai penghubung antara aplikasi dengan telepon seluler. Hasil dari penelitian ini berupa aplikasi layanan SMS Gateway yang dapat memberikan informasi akademik mahasiswa kepada orang tua.
\end{abstract}

Kata kunci: SMS gateway, STMIK, MDP, pendidikan, Gammu

(C) 2017 Jurnal RESTI

\section{Pendahuluan}

Penyebaran informasi saat ini sudah sangat pesat seiring perkembangan Teknologi Informasi (TI) yang memungkinkan informasi dapat tersebar ke mana saja dan kapan saja dengan sangat mudah. Sebagian perusahaan termasuk instansi pendidikan saat ini telah menerapkan teknologi informasi untuk mempermudah kegiatan operasionalnya dengan harapan dapat informasi yang akurat, relevan, dan tepat waktu.
STMIK Global Informatika (GI) MDP adalah salah satu perguruan tinggi swasta yang telah memanfaatkan teknologi informasi dalam kegiatan operasionalnya. Salah satunya adalah sistem informasi yang dapat mempermudah bagian akademik yaitu Simponi, yang merupakan akronim dari Sistem Pembelajaran Online dan Interaktif.

Simponi secara umum digunakan oleh dua pengguna yaitu dosen dan mahasiswa. Simponi dimanfaatkan sebagai media penyebaran materi perkuliahan, pemberian dan pengumpulan tugas, penyebaran pengumuman, penyebaran informasi nilai perkuliahan, 
penyebaran silabus, penyebaran jadwal perkuliahan, telepon seluler atau perangkat lainnya untuk mengirim melihat indormasi detil pertemuan, dan melihat rekap atau menerima pesan pendek. Layanan SMS absensi. Sistem informasi ini berbasis website sehingga mengunakan kanal atau jalur teks dalam proses dapat diakses dari mana saja dan kapan saja melalui penyampaiannya, sehingga meskipun sang penerima browser komputer, laptop, maupun telepon seluler.

Sasaran pembangunan Simponi tidak hanya untuk mahasiswa tetapi juga untuk orang tua mahasiswa, dengan harapan semua informasi akademik juga sampai ke orang tua mahasiswa. Tetapi pada kenyataannya banyak orang tua yang tidak mengenal Simponi karena keterbatasan pengetahuan tentang penggunaan internet. Hal tersebut menyebabkan banyak orang tua yang tidak mengetahui informasi nilai per semester, rekap absen, jadwal perkuliahan, dan pengumuman-pengumuman penting mengenai perkuliahan anaknya.

Short Message Service (SMS) adalah salah satu layanan teknologi informasi yang berbasis telepon seluler. SMS gateway adalah media penyebaran informasi berbasis SMS yang telah ada sejak lama, bahkan sempat dianggap merupakan teknologi lama yang mulai ditinggalkan. Akan tetapi saat ini SMS gateway sudah kembali digunakan oleh instansiinstansi sebagai salah satu alat pengelola informasi selain welalui website. SMS dianggap sebagai dua fungsi utama yang sering digunakan oleh masyarakat untuk berkomunikasi [1]. SMS dianggap media distribusi informasi penting di Indonesia, misal di Parlemen [1], Pelayanan publik [2] dan Pendidikan [3, 4]. Beberapa penelitian yang membahas tentang penggunaan teknologi SMS gateway salah satunya untuk mengontrol Air Conditioner di ruangan server. dari jarak jauh menggunakan SMS gateway berbasis mikrokontroler ATMEGA 16 dengan waktu akses tercepat 6,756 detik [5].

Jika dibandingkan dari segi kecepatan waktu, penyebaran informasi melalui website akan kalah cepat dibandingkan dengan penyebaran informasi melalui SMS gateway [Mira]. Selain itu, Hal ini disebabkan, ketika ada sebuah informasi baru yang disebarkan melalui website, pengguna tidak akan langsung tau karena tidak ada notifikasi. Sedangkan dengan media SMS gateway, pengguna dapat langsung mengetahui informasi yang disebarkan tersebut tanpa harus menggunakan jaringan internet.

Selain itu, saat ini di Indonesia terutama di Palembang, sebagian besar orang tua yang memiliki anak yang duduk di bangku perkuliahan masih asing dengan penggunaan internet, sehingga penyebaran informasi melalui website pun menjadi lambat. Maka dari itu, diusulkan penyebaran informasi yang selama ini dilakukan hanya melalui Simponi, akan dilakukan juga melalui SMS gateway.

\section{Tinjauan Pustaka}

\subsection{Short Message Service (SMS)}

Short Message Service (SMS) merupakan sebuah media yang diciptakan untuk berkomunikasi melalui SMS sedang melakukan kegiatan pembicaraan dengan handphone nya, SMS tetap dapat diterima [6].

SMS dibagi menjadi tiga jenis sebagai berikut [7]

1. SMS Premium: jenis aplikasi SMS dua arah dengan menggunakan 4 digit nomor unik seperti 96xx. Contohnya adalah SMS Quiz dan SMS Polling.

2. SMS Broadcast/ Blast/ Bulk/ Bomber: jenis aplikasi SMS satu arah berupa pengiriman pesan ke banyak nomor sekaligus. Contohnya adalah SMS Promo dan SMS Kampanye.

3. SMS Gateway: jenis SMS dua arah, dengan keunikan bahwa semua tarif yang diberlakukan adalah tarif SMS normal sesuai dengan apa yang diberlakukan oleh operator. Karena sifatnya yang dua arah, maka jenis SMS ini sangat cocok dijadikan sebagai SMS center organisasi atau institusi.

\subsection{SMS Gateway}

Gateway berarti pintu gerbang. Pola kerja SMS gateway yaitu dengan cara mengubah pesan pada lalu lintas jaringan seluler dari media lain atau sebaliknya. SMS gateway memungkinkan transmisi atau penerimaan pesan SMS dengan atau tanpa menggunakan telepon seluler.

Pada prinsipnya, SMS gateway adalah sebuah perangkat lunak yang menggunakan bantuan komputer dan memanfaatkan teknologi seluler yang diintegrasikan untuk mendistribusikan pesan-pesan yang diturunkan lewat sistem informasi melalui media SMS yang dikerjakan oleh jaringan seluler, perhatikan Gambar 1 [8]. Kelebihan SMS gateway adalah aplikasinya berbasis komputer sehingga dapat dijalankan dan dapat menyimpan data dalam jumlah banyak karena disimpan dalam sebuah hardisk server.

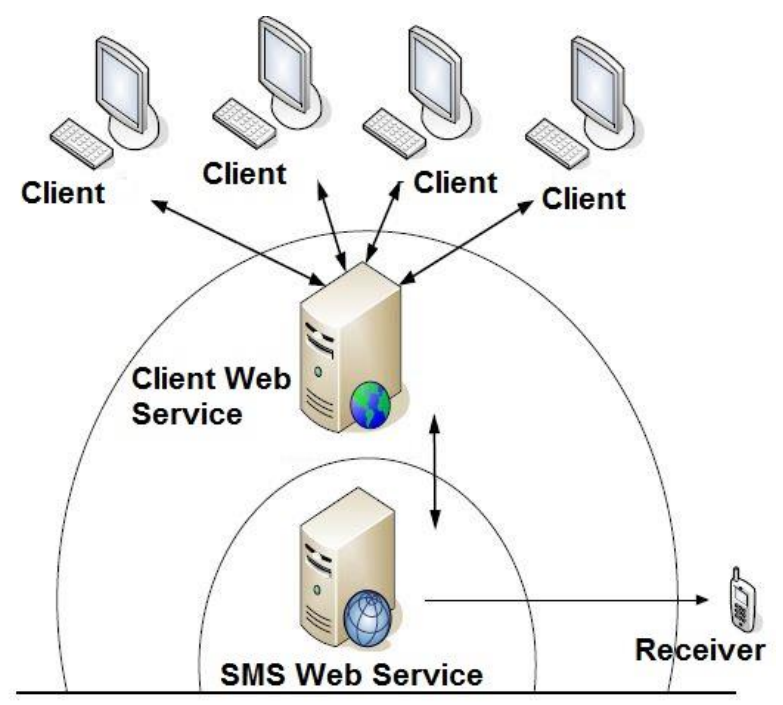

Gambar 1 Konsep Layanan SMS Gateway 
Sebuah penelitian mengusulkan konsep desain layanan Penelitian serupa juga pernah dilakukan dengan judul pesan singkat menggunakan SMS gateway dengan "Pengembangan Sistem Informasi SMS Gateway beberapa tingkatan. Tingkat pertama yaitu pengguna dalam Meningkatkan Layanan Komunikasi Sekitar akan mengakses aplikasi berbasis website dengan Akademika Fakultas Ilmu Komputer Universitas memasukkan informasi dasar pengiriman SMS seperti Sriwijaya”. Penelitian ini dilakukan untuk nomor penerima dan pesan yang dikirim ke penerima. mempermudah penyebaran undangan rapat, Pesan dikirim ke tingkat kedua yaitu pada tingkat web mengingatkan tugas, dan penyebaran pengumumanserver yang akan mengubah pesan dengan menerapkan pengumuman penting dalam lingkungan Fakultas Ilmu beberapa header keamanan untuk SMS dan Komputer Universitas Sriwijaya [10]. menyebarkannya ke SMS gateway. Lalu pesan akan dikirim ke telepon seluler penerima [8].

\section{Metodologi Penelitian}

Contoh penerapan SMS gateway adalah untuk Penelitian ini dilakukan pada STMIK GI MDP yang meneruskan e-mail kepada telepon seluler penerima. bertempat di Jl. Rajawali No. 14 Palembang. Untuk Sistem ini dikembangkan untuk meningkatkan mempermudah penelitian, diperlukan metode sebagai keamanan gateway pengguna. Pesan juga dapat dikirim pedoman dalam melakukan penelitian yang tergambar ke ratusan nomor tanpa harus mengetik nomor satu pada diagram alir penelitian yang dapat dilihat pada persatu karena semua nomor akan diambil secara Gambar 2. otomatis dari database. SMS gateway kadang membutuhkan lebih dari satu modem untuk berbagai macam urusan yang berbeda-beda. Karena pengakses SMS cukup banyak dan multi operator, maka dibutuhkan layanan yang murah untuk semua operator.

\subsection{Gammu}

Gammu adalah suatu aplikasi perangkat lunak yang bertindak sebagai salah satu modul SMS gateway yang dapat digabungkan dengan bahasa pemrograman. Gammu berfungsi untuk menghubungkan antara komputer dengan telepon seluler dan dapat dikoneksikan dengan berbagai macam merek telepon seluler. Gammu menggunakan bahasa $\mathrm{C}$ dan bersifat open source [7]. Berikut beberapa kelebihan Gammu:

1. Dapat berjalan dengan baik pada perangkat komputer dengan sistem operasi berbasis Windows maupun LINUX.

2. Mendukung banyak perangkat, baik itu HP maupun Modem GSM.

3. Menggunakan database MySQL yang bersifat open source.

4. Interface untuk aplikasi, bisa menggunakan clientserver maupun web based (PHP, ASP, ASP.Net, maupun J2EE).

\subsection{Penelitian Terdahulu}

Sebelumnya sudah banyak penelitian yang bertemakan tentang SMS gateway. Salah satunya berjudul "Aplikasi SMS Gateway sebagai Sarana Penunjang Informasi Perpustakaan pada Sekolah Menengah Pertama Negeri 1 Arjosari”. Penelitian tersebut mengembangkan sistem informasi perpustakaan yang dilengkapi dengan fitur SMS gateway untuk memudahkan petugas dalam menyebarkan informasi kepada siswa [4].

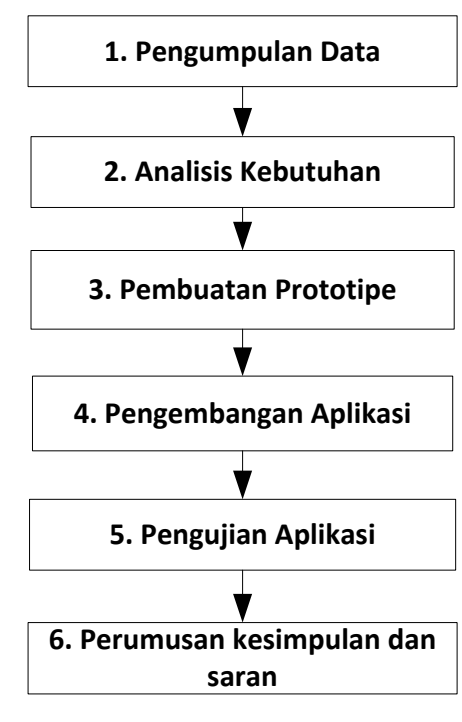

Gambar 2 Diagram Alir Penelitian

Berikut langkah-langkah penelitian ini:

\subsection{Pengumpulan Data}

Kegiatan pengumpulan data dilakukan untuk menemukan data primer dan sekunder. Pengumpulan data primer dilakukan dengan cara melakukan observasi dan melakukan wawancara terhadap pengguna Simponi, sedangkan pengumpulan data sekunder didapat melalui studi literatur.

\subsection{Analisis Kebutuhan}

Tahap analisis kebutuhan dilakukan untuk memastikan kebutuhan yang harus ada pada sistem yang dibuat. Analisis kebutuhan dalam penelitian ini dijelaskan menggunakan usecase diagram yang dapat dilihat pada Gambar 3.

Penelitian selanjutnya berjudul "Sistem Informasi Akademik Berbasis SMS Gateway". Penelitian ini 3.3 Pembuatan Prototipe

bertujuan untuk mempermudah penyebaran informasi Setelah mendapatkan serta mengetahui seluruh kepada orang tua/ wali siswa terkait prestasi dan kebutuhan yang diperlukan dalam pengembangan perilaku siswa selama di sekolah [9]. 
sistem, maka dilakukan tahap pembuatan prototipe. 3.6 Perumusan Kesimpulan dan Saran

Prototipe dianggap baik untuk mendefenisikan sistem yang akan dibuat kepada pengguna dan dapat digunakan untuk menyambungkan ketidakpahaman pengguna mengenai hal teknis dan memperjelas spesifikasi kebutuhan yang diinginkan pengguna kepada pengembang perangkat lunak. Dengan adanya prototipe, pengguna akan lebih mudah menspesifikasikan secara detail sistem yang diinginkan dari segi masukan, proses, dan keluaran.

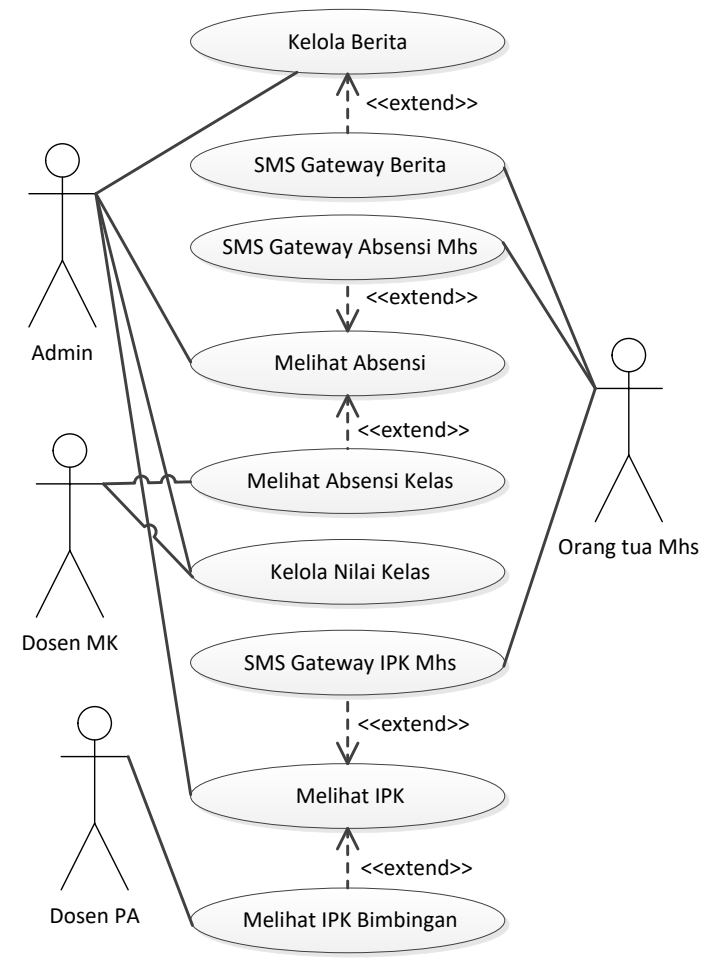

Gambar 3 Use Case Diagram

\subsection{Pengembangan Aplikasi}

Setelah tahap pembuatan prototipe, maka tahap selanjutnya adalah melakukan pengembangan aplikasi atau pengkodean. Aplikasi ini dibuat berbasis website dengan menggunakan Bahasa Pemrograman Ruby dengan framework Ruby and rails dan memanfaatkan fitur SMS Gateway.

\subsection{Pengujian Aplikasi}

Setelah aplikasi SMS gateway selesai dibuat, maka diperlukan pengujian untuk memastikan tidak ada kesalahan dalam pengembangan sehingga dapat digunakan. Pengujian menggunakan metode black box testing yaitu pengujian perangkat lunak tanpa melihat struktur kode program, melainkan hanya menilai dari fungsional fitur aplikasi. Dilakukan juga uji coba dengan mengirimkan SMS sesuai dan tidak sesuai format.
Tahap ini merupakan tahap akhir dari penelitian ini. Aplikasi SMS gateway yang dibuat telah diuji, kemudian dapat ditarik kesimpulan dan saran.

\section{Hasil dan Pembahasan}

Hasil dari penelitian ini berupa sebuah fitur SMS Gateway yang diintegrasikan pada SIMPONI yang terdapat pada STMIK GI MDP. Alur proses kerja SMS Gateway yang dapat dilihat pada Gambar 4.

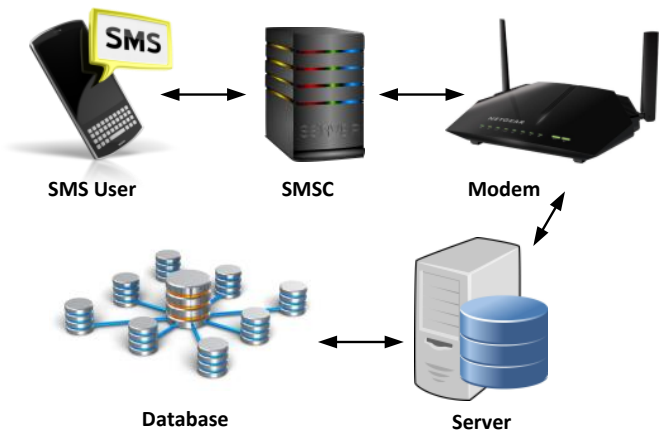

Gambar 4 Alur Proses Kerja SMS Gateway

Pengguna dapat mengirimkan dan menerima SMS melalui sistem ini. Adapun SMS yang diterima pengguna adalah tentang IPK, berita, dan absensi per matakuliah mahasiswa. Pengguna dapat melakukan permintaan informasi IPK dan absensi dengan mengirimkan SMS dengan format yang dapat dilihat pada Tabel 1 .

Tabel 1 Format Request SMS

\begin{tabular}{|l|l|}
\hline \multicolumn{1}{|c|}{ Keyword } & \multicolumn{1}{|c|}{ Hasil } \\
\hline IPK $<$ NPM $>$ & IPK $<$ Nama $><$ IPK $>$ \\
\hline ABSENSI & $\begin{array}{l}\text { Persentase Absensi } \\
<\text { NamaMK }> \\
<\text { KODEMK }>\langle\text { NPM }>\end{array}$ \\
\hline Format Salah & $\begin{array}{l}\text { Maaf Format Anda } \\
\text { salah }\end{array}$ \\
\hline
\end{tabular}

Setiap SMS yang akan dikirimkan oleh sistem, akan disimpan ke dalam database pada tabel Sentitem. Untuk mengirimkan SMS ke pengguna dibutuhkan aplikasi Gammu yang menghubungkan server dengan modem.

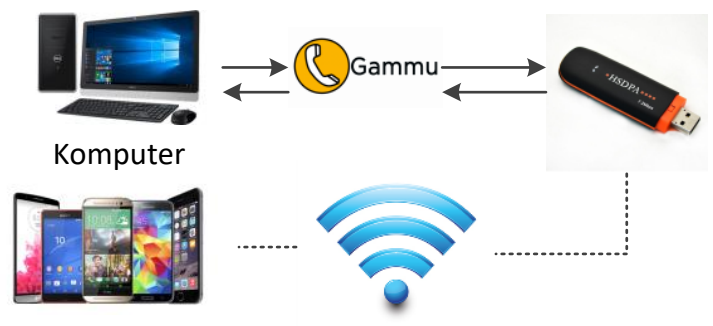

Ponsel Penerima

Gambar 5 Cara Kerja Gammu 
SMS yang dikirimkan oleh pengguna akan diterima oleh modem, kemudian SMS tersebut akan diambil oleh Gammu untuk dipindahkan ke dalam tabel yang ada di database sesuai dengan yang telah diatur sebelumnya. Ilustrasi cara kerja Gammu dapat dilihat pada Gambar 5.

Database Management System (DBMS) yang digunakan pada penelitian ini adalah MySQL. Dalam database yang digunakan terdapat 19 tabel, salah satunya adalah tabel Sentitem yang berfungsi untuk menampung draft SMS yang akan dikirimkan ke pengguna dengan kondisi tertentu.

Gammu akan mengirimkan data setiap baris tabel Sentitem ke modem utuk dikirimkan ke nomor tujuan. Setelah modem berhasil mengirimkan SMS, sistem akan memindahkan data yang telah dikirm ke dalam tabel Outbox dan menghapus baris tersebut dari Sentitem. Database yang digunakan pada sistem ini dapat dilihat pada Gambar 6 .

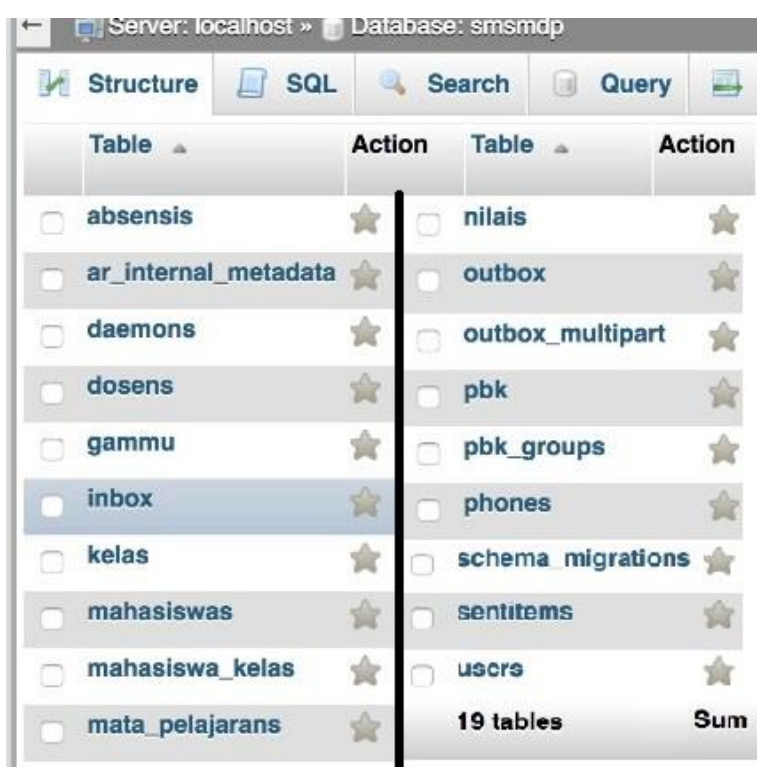

Gambar 6 Database SIMPONI

Gambar 7 menampilkan Halaman Menu Utama Admin dari aplikasi yang dibangun. Melalui halaman utama ini, Admin dapat mengakses beberapa menu yang diperlukan untuk kegiatan operasional akademik yang terhubung dengan SMS Gateway, salah satunya fitur absensi.

Gambar 8 merupakan tampilan halaman absensi mahasiswa yang dapat diakses oleh Admin. Pada halaman ini ditampilkan data absensi seluruh mahasiswa aktif pada STMIK GI MDP. Sedangkan dosen Pembimbing Akademik (PA) hanya dapat melihat absensi dari mahasiswa yang di bawah bimbingannya saja, dan dosen pengampu mata kuliah hanya dapat melihat absensi dari mahasiswa yang berada di kelas yang diampunya saja. Setiap perkuliahan berakhir, tabel ini akan di-update dan dilakukan perhitungan persentase absensi secara otomatis.

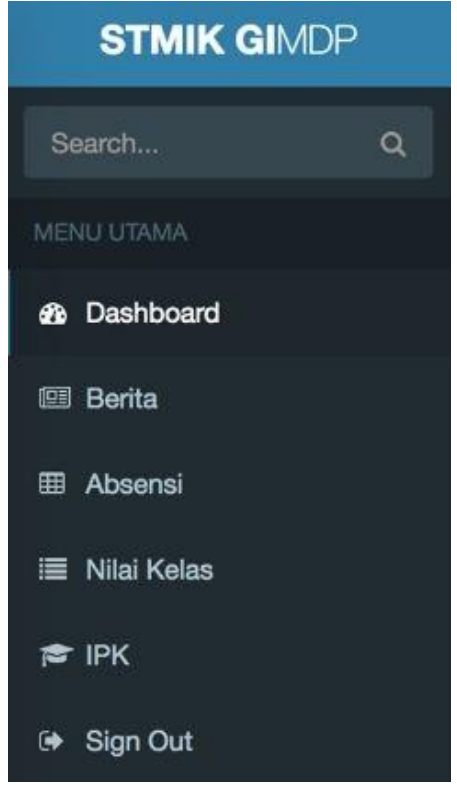

Gambar 7 Halaman Menu Utama Admin

\begin{tabular}{|c|c|c|}
\hline \multicolumn{2}{|c|}{ Absensi } & \multirow[t]{2}{*}{ Cari Mahasiswa } \\
\hline 口 & B Simpan & \\
\hline$\square$ & Abdul Mustofa & Hadir $100 \%$ - 10 dari 10 pertemuan \\
\hline$\square$ & Ahmad Rivai & Hadir $100 \%$ - 10 dari 10 pertemuan \\
\hline$\square$ & Bastian & Hadir $100 \%$ - 10 dari 10 pertemuan \\
\hline$\square$ & Doni Rahmadani & Hadir $100 \%$ - 10 dari 10 pertemuan \\
\hline$\square$ & FX Robert & Hadir $100 \%$ - 10 dari 10 pertemuan \\
\hline$\square$ & Gabriel Setiawan & Hadir $100 \%$ - 10 dari 10 pertemuan \\
\hline$\square$ & Liana Sari & Hadir $100 \%$ - 10 dari 10 pertemuan \\
\hline$\square$ & Muhammad Saba & Hadir $90 \%$ - 9 dari 10 pertemuan \\
\hline$\square$ & Nita Pratiwi & Hadir $100 \%$ - 10 dari 10 pertemuan \\
\hline D & Silviana Julian & Hadir $100 \%$ - 10 dari 10 pertemuan \\
\hline
\end{tabular}

Gambar 8 Halaman Absensi Mahasiswa

Gambar 9 merupakan tampilan halaman daftar SMS yang akan dikirimkan oleh sistem. Sistem mengirimkan SMS kepada nomor-nomor yang terdaftar secara otomatis, sesuai dengan kriteria yang telah ditentukan. Pada contoh di Gambar 9, kriterianya adalah Indeks Prestasi Kumulatif (IPK) mahasiswa yang di bawah 2,5. Sesuai dengan kebijakan yang ada pada STMIK GI MDP, seluruh mahasiswa aktif yang memiliki IPK kurang dari 2,5, akan dipanggil orang tuanya untuk diberikan arahan.

Gambar 10 merupakan tampilan SMS yang diterima oleh nomor orang tua mahasiswa setelah sebelumnya sudah dilakukan pengiriman secara otomatis oleh sistem yang terlihat pada Gambar 9. Nomor orang tua mahasiswa sebelumnya telah didaftarkan pada sistem, 
sehingga sistem dapat mengirimkan SMS kepada orang tua secara otomatis, sesuai dengan kriteria yang telah ditentukan.

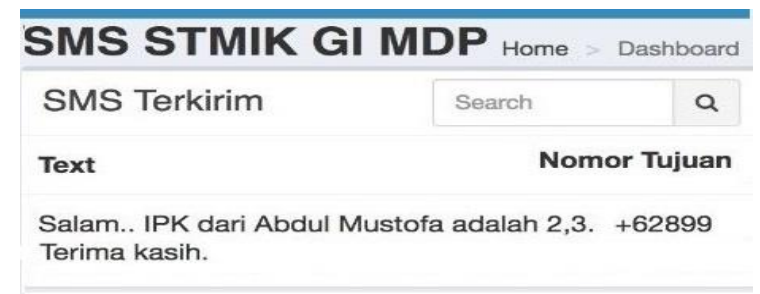

Gambar 9 Halaman Daftar SMS yang akan Dikirim

Adapun SMS yang akan diterima orang tua mahasiswa dari sistem ini selain informasi IPK adalah informasi absensi, informasi nilai per mata kuliah, dan berita akademik. Informasi absensi akan dikirimkan dengan kriteria kehadiran mahasiswa kurang dari $70 \%$ per mata kuliah. SMS tentang informasi absensi akan dikirimkan setelah pertemuan ke-6. SMS tentang nilai akan dikirim kepada orang tua pada saat nilai telah diterbitkan, atau setelah masa Ujian Akhir Semester (UAS).

\section{:E:}

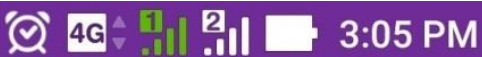

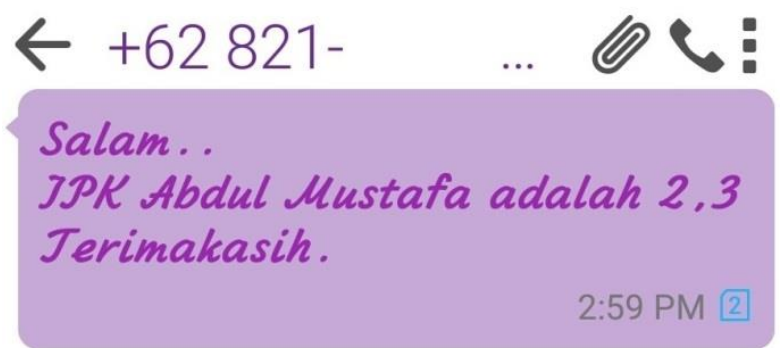

Gambar 10 Tampilan SMS untuk Orangtua

\section{Kesimpulan}

\subsection{Simpulan}

Setelah penjelasan pada bagian sebelumnya, maka dapat ditarik kesimpulan dari penelitian ini sebagai berikut.

1. Aplikasi SMS Gateway yang dibuat memiliki fitur monitoring absensi, nilai mata kuliah, IPK, dan berita akademik.

2. Dengan penerapan aplikasi SMS Gateway pada STMIK GI MDP, dapat meningkatkan pelayanan terkait informasi akademik kepada orang tua mahasiswa.

\subsection{Saran}

Aplikasi ini diharapkan tidak hanya digunakan pada lingkungan STMIK GI MDP, melainkan dapat digunakan pada perguruan tinggi lain. Peneliti selanjutnya diharapkan mampu mengembangkan aplikasi yang lebih kompleks seiring dengan perkembangan teknologi. Untuk penerapan SMS gateway menggunakan aplikasi Gammu, dibutuhkan waktu jeda selama 1 menit untuk mengirimkan SMS berikutnya, disarankan menggunakan aplikasi yang berbayar agar dapat mengirimkan SMS ke banyak nomor dengan waktu yang lebih cepat.

\section{Daftar Rujukan}

[1] Persada, Satria, at all. (2013). Toward Paperless Public Announcement on Environmental Impact Assessment (EIA) through SMS Gateway in Indonesia. International Conference on Sustainable Future for Human Security ${ }^{\text {th }}$ pp 271-279.

[2] Haryanto. (2010). Implementasi SMS Gateway untuk Penjualan Pulsa Elektrik Menggunakan PHP dan MySQL di Rumah Sakit. Jurnal Ilmiah Rekam Medis dan Informatika Kesehatan, No.1. Vol. 1. pp.50-57.

[3] Taufiq, M. dan Eka, B. (2013). Pengembangan Aplikasi SMS Gateway untuk Informasi Pendaftaran Peserta Didik Baru di SMAN 1 Jepara. Indonesian Jurnal on Networking and Security Vol. 2, No. 1, pp. 50-55.

[4] Nurleala, Fetty. (2013). Aplikasi SMS Gateway sebagai Sarana Penunjang Informasi Perpustakaan pada Sekolah Menengah Pertama Negeri 1 Arjosari. Indonesian Journal on Networking and Security, No.2 Vol 4. pp. 20-25.

[5] Alfarisi, Gemma, at all. (2013). Implementasi Sistem SMS Gateway untuk Kendali Air Conditioner. Jurnal Online Institut Teknologi Nasional, No. 2. Vol.1. pp. 142-151

[6] Sadeli, Muhammad. 2012. Aplikasi SMS dengan Visual Basic 6.0 dan Visual Basic2010, Maxikom, Yogyakarta

[7] Wahidin. 2010. Aplikasi SMS dengan PHP untuk Orang Awam. Palembang:Maxikom

[8] Katankar, V.K. \& Thakare, D.V.M., 2010. Short Message Service using SMS Gateway. International Journal on Computer Science and Engineering (IJCSE) Vol. 02, No. 04. pp. 1487-1491.

[9] Suryani 2008, Rancang Bangun Sistem Informasi Sekolah Via SMS Gateway Berbasis CMS, Diakses dari http://lib.uinmalang.ac.id/> pada tanggal 23 Agustus 2012

[10] Wiharto, Yudi. (2011). Sistem Informasi Akademik Berbasis SMS Gateway. Jurnal Teknologi dan Informatika Vol. 1 No.2.

[11] Afrina, M., dan Ibrahim, A., (2015). Pengembangan Sistem Informasi SMS Gateway Dalam Meningkatkan Layanan Komunikasi Sekitar Akademika Fakultas Ilmu Komputer Universitas Sriwijaya. Jurnal Sistem Informasi Vol. 7, No. 2. pp. 852-864. 